\title{
No difference in enterotoxin production among Staphylococcus aureus strains isolated from blood compared with strains isolated from healthy carriers
}

\author{
B. L. RØDER, N. H. R. ERIKSEN, L. P. NIELSEN, T. SLOTSBJERG, VIBEKE T. ROSDAHL \\ and F. ESPERSEN
}

Division of Preventive Microbiology, Statens Seruminstitut, Artillerivej 5, DK-2300 Copenhagen S, Denmark

\begin{abstract}
Summary. The production of enterotoxin A, B, C and D by 196 Staphylococcus aureus strains isolated from blood cultures and 95 strains from nasal carriers was investigated. Half of the bacteraemia strains were from patients who died with or because of their infection, the other half from patients who survived. The nasal strains were selected to match the bacteraemia strains regarding phage types. Overall, $30.6 \%$ of the bacteraemia strains and $40.0 \%$ of the nasal strains produced enterotoxins; enterotoxins $B$ and $C$ were the toxins produced most frequently in both groups. A similar incidence and pattern of enterotoxin production was found among the bacteraemia strains of $S$. aureus regardless of acquisition of the infection, the portal of entry, presence or absence of endocarditis and outcome of the infection. Thus, the concept that the enterotoxins play an important role in staphylococcal infections, apart from the diseases caused by the toxins per se such as food poisoning and toxic shock syndrome, cannot be substantiated by the results of the present study.
\end{abstract}

\section{Introduction}

The staphylococcal enterotoxins are a series of biologically active proteins known to be responsible for staphylococcal food poisoning. ${ }^{1}$ Evidence has accumulated to indicate that the enterotoxins may play a role in some cases of toxic shock syndrome (TSS). ${ }^{2,3}$ Furthermore, animal studies have shown that intravenous injection of enterotoxins $A$ and $B$ into rhesus monkeys can produce many of the signs and symptoms associated with TSS. ${ }^{1}$ Crass and Bergdoll ${ }^{2}$ examined Staphylococcus aureus isolates from 55 patients, who had either confirmed or probable nonmenstrual TSS, and found that eight of the isolates did not produce toxic shock syndrome toxin-1 (TSST-1), but these strains produced staphylococcal enterotoxin B.

Whether the enterotoxins play other roles in the pathogenesis of serious infections caused by $S$. aureus is debated and still remains unclear. However, recently Humphreys et al $^{4}$ reported a higher incidence of enterotoxin production among isolates from patients with septicaemia than among nasal isolates from healthy people.

The aim of the present study was to investigate the

Received 25 May 1994; accepted 16 July 1994. incidence of enterotoxin production among $S$. aureus bacteraemia isolates from patients with different types of infection, different portals of entry and with different outcome of the infection.

\section{Materials and methods}

In Denmark almost all $S$. aureus strains isolated from blood cultures are referred to the Staphylococcus Laboratory, Statens Seruminstitut, for phage typing. The hospital departments involved are asked to provide further clinical information, which is achieved in all but a few cases. A number of clinical data are recorded, including the presence of endocarditis and osteomyelitis or arthritis, portal of entry, such as lungs, post-operative wounds, skin or unknown, whether the infection is nosocomial or communityacquired and the outcome (morbidity or lethality) of the infection.

\section{Bacterial strains}

The study was conducted in three parts. In the first part, the incidence of enterotoxin production among isolates originating from patients with bacteraemia of 
different acquisition, different portals of entry, with and without endocarditis or haematogenous bone or joint involvement, and with different outcomes of the infection were examined. For this purpose, some of the staphylococcal strains isolated from blood in 1991 were investigated. Strains which were isolated from a single blood culture yielding two (or more) different $S$. aureus strains were excluded. The rest of the isolates were divided into two subpopulations: (1) the isolates originating from patients who died with or because of their bacteraemia, and (2) the isolates originating from patients who survived their bacteraemic episode. From the first subpopulation (patients who died) the following groups were selected sequentially: (a) 17 isolates from patients with endocarditis, (b) 25 isolates from patients with haematogenous osteomyelitis or arthritis, (c) 39 isolates from patients with pneumonia and (d) 17 isolates from patients with bacteraemia due to deep wound infection. Next, for these 98 isolates it was determined whether infection was present on admission (community-acquired), nosocomial or unknown. From the second subpopulation (living patients), $98 \mathrm{~S}$. aureus isolates were selected with comparable infections, portals of entry and source of acquisition of $S$. aureus. The results of this first part of the study showed a higher incidence of enterotoxin production among the strains belonging to phage group III originating from patients who died compared with the incidence of enterotoxin production among phage group III strains which originated from patients who survived. Therefore, in the second part of the study we investigated this aspect further. From the original collection of bacteraemia strains from 1991, all the remaining isolates belonging to phage group III ( 89 isolates) were examined to determine the incidence of enterotoxin production.

In the third part of the study, the incidence of enterotoxin production was examined in $95 \mathrm{~S}$. aureus isolates from the anterior nares which were collected during a study of nasal carriage of staphylococci amongst healthy people. ${ }^{5}$ The incidence of enterotoxin production has been reported to differ between different phage groups, and, therefore, the nasal carriage strains were selected to correspond to the bacteraemia strains examined in the first part of the study with regard to phage groups. The 95 isolates were picked from a total of 183 isolates. The only differences between the 95 and 183 isolates were a higher frequency $(24.2 \%$ versus $13 \cdot 1 \%)$ of group II strains and a lower frequency of mixed types $(6 \cdot 3 \%$ versus $19 \cdot 1 \%)$ and non-typable strains $(8.4 \%$ versus $15 \cdot 8 \%)$.

\section{Bacteriophage typing}

Phage typing was performed according to the method of Blair and Williams ${ }^{6}$ with the present international set of typing phages. The subdivision into phage groups and complexes was done according to Parker.?

\section{Detection of $S$. aureus enterotoxins}

Production of $S$. aureus enterotoxins A, B, C and D was detected with kits purchased from Oxoid (Unipath) by means of reverse passive latex agglutination.

\section{Statistical analysis}

The $\chi^{2}$ test or Fisher's exact test were applied when appropriate; $\mathrm{p}<0.05$ was considered significant.

\section{Results}

A total of 1036 S. aureus strains isolated from blood cultures was referred to the Staphylococcus Laboratory in $1991 ; 18$ strains were excluded because they were isolated from blood cultures which yielded more than one strain. From the remaining 1018 isolates, 196 were examined for production of enterotoxin A, B, C and D in the first part of the study. Sixty $(30.6 \%)$ of the 196 bacteraemia isolates produced one or two enterotoxins; 53 produced a single enterotoxin and seven produced two. Enterotoxin production by the bacteraemia strains in relation to the different selection criteria is shown in table I. The isolates selected from patients with endocarditis showed a non-significantly higher frequency of enterotoxin production than those from patients without endocarditis $(41.2 \%$ versus $28.4 \%, p=0.21$ ), whereas the opposite was the case when the isolates from the patients with osteomyelitis or arthritis were compared with those from the patients without ( $18.5 \%$ versus $35.2 \%$ ), and this difference was statistically significant $(\mathrm{p}=0.03)$. Also, the incidence of production of enterotoxins in the endocarditis group was statistically higher than in the haematogenous osteomyelitis or arthritis group $(p=0.04)$. Considering the different portals of entry of the infections, only minor and non-significant differences in enterotoxin production were observed (table I). Whether the infection was hospital- or communityacquired or of unknown acquisition did not seem to be of any importance; almost identical incidences of enterotoxin production were found in the three categories. Thirty-two of the isolates $(32.7 \%)$ collected from patients who survived produced enterotoxins as compared with 28 isolates $(28.6 \%)$ from patients who died of, or with, their infection.

In table II, the 196 bacteraemia strains are divided according to phage-type pattern. The present investigation confirms that enterotoxin production occurs rarely among group II strains and that strains of type 95 predominantly produce enterotoxin $\mathrm{C}$ and strains of the 94/96 complex enterotoxin B. Within strains of each phage-type pattern, enterotoxin production was not significantly different in strains from patients who died compared with those who survived. However, a somewhat higher incidence of enterotoxin production was observed among group III strains 
Table I. Enterotoxin production by $196 \mathrm{~S}$. aureus strains isolated from blood cultures in Denmark in 1991

\begin{tabular}{|c|c|c|c|c|c|c|c|}
\hline \multirow{2}{*}{ Selection criteria } & & \multirow{2}{*}{$\begin{array}{l}\text { Number of } \\
\text { isolates }\end{array}$} & \multicolumn{5}{|c|}{$\begin{array}{c}\text { Number of isolates producing } \\
\text { enterotoxin }\end{array}$} \\
\hline & & & A & B & $\mathrm{C}$ & D & Total* (\%) \\
\hline Endocarditis & $\begin{array}{l}\text { Present } \\
\text { Absent }\end{array}$ & $\begin{array}{r}34 \\
162\end{array}$ & $\begin{array}{r}4 \\
14\end{array}$ & $\begin{array}{r}6 \\
16\end{array}$ & $\begin{array}{r}3 \\
19\end{array}$ & $\begin{array}{l}1 \\
4\end{array}$ & $\begin{array}{l}14(41 \cdot 2) \\
46(28 \cdot 4)\end{array}$ \\
\hline $\begin{array}{l}\text { Haematogenous } \\
\text { Osteomyelitis } \\
\text { and arthritis }\end{array}$ & $\begin{array}{l}\text { Present } \\
\text { Absent }\end{array}$ & $\begin{array}{r}54 \\
142\end{array}$ & $\begin{array}{r}5 \\
13\end{array}$ & $\begin{array}{r}3 \\
19\end{array}$ & $\begin{array}{r}4 \\
18\end{array}$ & $\begin{array}{l}1 \\
4\end{array}$ & $\begin{array}{l}10(18 \cdot 5) \\
50(35 \cdot 2)\end{array}$ \\
\hline Portal of entry & $\begin{array}{l}\text { Lungs } \\
\text { Post-operative } \\
\text { wounds } \\
\text { Skin } \\
\text { Unknown }\end{array}$ & $\begin{array}{l}83 \\
49\end{array}$ & $\begin{array}{l}0 \\
8\end{array}$ & $\begin{array}{l}8 \\
9\end{array}$ & $\begin{array}{l}1 \\
5\end{array}$ & $\begin{array}{l}2 \\
1\end{array}$ & $\begin{array}{r}24(28 \cdot 9) \\
18(36 \cdot 7) \\
2(20 \cdot 0) \\
16(29 \cdot 6)\end{array}$ \\
\hline Acquisition & $\begin{array}{l}\text { Hospital } \\
\text { Community } \\
\text { Unknown }\end{array}$ & $\begin{array}{r}81 \\
101 \\
14\end{array}$ & $\begin{array}{l}8 \\
9 \\
1\end{array}$ & $\begin{array}{r}10 \\
10 \\
2\end{array}$ & $\begin{array}{r}7 \\
12 \\
3\end{array}$ & $\begin{array}{l}1 \\
4 \\
0\end{array}$ & $\begin{array}{r}24(29 \cdot 6) \\
31(30 \cdot 7) \\
5(35 \cdot 7)\end{array}$ \\
\hline Outcome & $\begin{array}{l}\text { Died } \\
\text { Survived }\end{array}$ & $\begin{array}{l}98 \\
98\end{array}$ & $\begin{array}{l}9 \\
9\end{array}$ & $\begin{array}{r}7 \\
15\end{array}$ & $\begin{array}{r}13 \\
9\end{array}$ & $\begin{array}{l}3 \\
2\end{array}$ & $\begin{array}{l}28(28 \cdot 6) \\
32(32 \cdot 7)\end{array}$ \\
\hline All strains & & 196 & 18 & 22 & 22 & 5 & $60(30.6)$ \\
\hline
\end{tabular}

*Some isolates produced more than one enterotoxin, therefore the total may be less than the sum of the individual enterotoxins.

Table II. Enterotoxin production by 196 bacteraemia and 95 nasal carriage $S$. aureus isolates in relation to phage group

\begin{tabular}{|c|c|c|c|c|c|c|c|}
\hline \multirow{2}{*}{ Phage group } & \multirow{2}{*}{ Source } & \multirow{2}{*}{$\begin{array}{l}\text { Number of } \\
\text { isolates }\end{array}$} & \multicolumn{5}{|c|}{ Number of isolates producing enterotoxin } \\
\hline & & & A & $\mathbf{B}$ & $\mathrm{C}$ & $\mathrm{D}$ & Total* $(\%)$ \\
\hline “80" & $\begin{array}{l}\text { B } \\
\text { C }\end{array}$ & $\begin{array}{l}3 \\
2\end{array}$ & $\begin{array}{l}2 \\
0\end{array}$ & $\begin{array}{l}0 \\
1\end{array}$ & $\begin{array}{l}0 \\
0\end{array}$ & $\begin{array}{l}0 \\
0\end{array}$ & $\begin{array}{l}2(66 \cdot 7) \\
1(50 \cdot 0)\end{array}$ \\
\hline I & $\begin{array}{l}\text { B } \\
\text { C }\end{array}$ & $\begin{array}{l}20 \\
10\end{array}$ & $\begin{array}{l}7 \\
1\end{array}$ & $\begin{array}{l}4 \\
1\end{array}$ & $\begin{array}{l}1 \\
1\end{array}$ & $\begin{array}{l}0 \\
0\end{array}$ & $\begin{array}{r}11(55 \cdot 0) \\
3(30 \cdot 0)\end{array}$ \\
\hline II & $\begin{array}{l}\mathrm{B} \\
\mathrm{C}\end{array}$ & $\begin{array}{l}45 \\
23\end{array}$ & $\begin{array}{l}0 \\
1\end{array}$ & $\begin{array}{l}1 \\
0\end{array}$ & $\begin{array}{l}1 \\
0\end{array}$ & $\begin{array}{l}0 \\
0\end{array}$ & $\begin{array}{l}2(4 \cdot 4) \\
1(4 \cdot 3)\end{array}$ \\
\hline III & $\begin{array}{l}\mathrm{B} \\
\mathrm{C}\end{array}$ & $\begin{array}{l}19 \\
10\end{array}$ & $\begin{array}{l}4 \\
0\end{array}$ & $\begin{array}{l}1 \\
1\end{array}$ & $\begin{array}{l}2 \\
0\end{array}$ & $\begin{array}{l}3 \\
3\end{array}$ & $\begin{array}{l}7(36 \cdot 8) \\
4(40 \cdot 0)\end{array}$ \\
\hline $83 \mathrm{~A}$ & $\begin{array}{l}\text { B } \\
\text { C }\end{array}$ & $\begin{array}{r}16 \\
4\end{array}$ & $\begin{array}{l}2 \\
0\end{array}$ & $\begin{array}{l}2 \\
0\end{array}$ & $\begin{array}{l}0 \\
1\end{array}$ & $\begin{array}{l}1 \\
2\end{array}$ & $\begin{array}{l}3(18 \cdot 8) \\
3(75 \cdot 0)\end{array}$ \\
\hline $94 / 96$ & $\begin{array}{l}\text { B } \\
\text { C }\end{array}$ & $\begin{array}{l}25 \\
11\end{array}$ & $\begin{array}{l}0 \\
1\end{array}$ & $\begin{array}{r}12 \\
5\end{array}$ & $\begin{array}{l}1 \\
0\end{array}$ & $\begin{array}{l}0 \\
0\end{array}$ & $\begin{array}{r}13(52 \cdot 0) \\
6(54 \cdot 5)\end{array}$ \\
\hline 95 & $\begin{array}{l}\text { B } \\
\text { C }\end{array}$ & $\begin{array}{l}41 \\
21\end{array}$ & $\begin{array}{l}0 \\
1\end{array}$ & $\begin{array}{l}1 \\
0\end{array}$ & $\begin{array}{r}12 \\
6\end{array}$ & $\begin{array}{l}1 \\
1\end{array}$ & $\begin{array}{r}13(31 \cdot 7) \\
8(38 \cdot 1)\end{array}$ \\
\hline Mixed & $\begin{array}{l}\text { B } \\
\text { C }\end{array}$ & $\begin{array}{r}11 \\
6\end{array}$ & $\begin{array}{l}2 \\
1\end{array}$ & $\begin{array}{l}1 \\
0\end{array}$ & $\begin{array}{l}1 \\
4\end{array}$ & $\begin{array}{l}0 \\
0\end{array}$ & $\begin{array}{l}4(36 \cdot 4) \\
5(83 \cdot 3)\end{array}$ \\
\hline Non-typable & $\begin{array}{l}\text { B } \\
\text { C }\end{array}$ & $\begin{array}{r}16 \\
8\end{array}$ & $\begin{array}{l}1 \\
0\end{array}$ & $\begin{array}{l}0 \\
0\end{array}$ & $\begin{array}{l}4 \\
7\end{array}$ & $\begin{array}{l}0 \\
0\end{array}$ & $\begin{array}{l}5(31 \cdot 2) \\
7(87 \cdot 5)\end{array}$ \\
\hline Total & $\begin{array}{l}\text { B } \\
\text { C }\end{array}$ & $\begin{array}{r}196 \\
95\end{array}$ & $\begin{array}{r}18 \\
5\end{array}$ & $\begin{array}{r}22 \\
8\end{array}$ & $\begin{array}{l}22 \\
19\end{array}$ & $\begin{array}{l}5 \\
6\end{array}$ & $\begin{array}{l}60(30 \cdot 6) \\
38(40 \cdot 0)\end{array}$ \\
\hline
\end{tabular}

B, bacteraemia; C, nasal carriage.

* Some isolates produced more than one enterotoxin, therefore the total may be less than the sum of the individual enterotoxins.

from patients who died, compared to those from patients who survived. Therefore, another 89 strains belonging to phage group III, giving a total of 108 bacteraemia $S$. aureus isolates, were examined for enterotoxin production. However, with this larger number of strains no differences were detected between the incidence of enterotoxin production among the isolates originating from patients who died $(46 \cdot 2 \%, 12$ of 26$)$ and those from patients who survived (37.8\%, 31 of 82 ).

In table II enterotoxin production by the 95 nasal carriage $S$. aureus isolates in relation to phage group is also shown. Overall, $38(40.0 \%)$ of the nasal strains produced enterotoxins; an incidence very similar to the one observed among the bacteraemia strains $(30.6 \%)$. None of the nasal isolates produced more 
than one enterotoxin. Considering the different phage groups, the nasal strains belonging to phage group $83 \mathrm{~A}(75.0 \%)$ and the mixed group $(83.3 \%)$ produced enterotoxins more frequently than the corresponding bacteraemia strains $(18.8 \%$ and $36.4 \%$, respectively). However, none of these differences was statistically significant $(p=0 \cdot 12$ and $p=0 \cdot 18)$. The only statistically significant difference was found in the nontypable group where seven of eight $(87.5 \%)$ nasal strains produced enterotoxin compared with $31.2 \%$ of the bacteraemia strains $(p=0.03)$. The pattern of enterotoxin production was similar in the bacteraemia and nasal carriage groups; enterotoxins $\mathrm{C}$ and $\mathrm{B}$ were the toxins produced most frequently.

\section{Discussion}

S. aureus strains may produce several exo-enzymes and toxins with a considerable range of biological activities. ${ }^{8}$ Only a few staphylococcal diseases, including staphylococcal scalded skin syndrome and TSS, have been related to toxin production ${ }^{9,10}$ and the exact significance of many of the extracellular proteins in the pathogenesis of infection remains obscure. This holds true even for the staphylococcal enterotoxins, which until recently have not been linked to specific diseases apart from food poisoning. However, it now seems reasonably substantiated that enterotoxin $B$ is responsible for a few cases of non-menstrual TSS. ${ }^{2,3}$

In the present study the incidence of enterotoxin production among $196 S$. aureus strains isolated from blood cultures was examined. The bacteria were isolated from two subpopulations of patients differing from each other in what was believed to be the most crucial parameter-mortality. Very similar patterns of enterotoxin production were observed amongst the strains from patients who died compared with strains from patients who survived, which strongly disfavours the theory that the enterotoxins play a particularly important role in the ultimate outcome of infection. Similarly, in another study of Danish S. aureus strains, no statistically significant difference was found in the frequency of TSST-1 production between bacteraemia strains from patients who died and those from patients

\section{References}

1. Bergdoll MS. Enterotoxins. In: Easmon CSF, Adlam C (eds) Staphylococci and staphylococcal infections, vol 2. The organism in vivo and in vitro. London, Academic Press. 1983: 559-598.

2. Crass BA, Bergdoll MS. Involvement of staphylococcal enterotoxins in nonmenstrual toxic shock syndrome. $J$ Clin Microbiol 1986; 23: 1138-1139.

3. Schlievert PM. Staphylococcal enterotoxin B and toxic-shock syndrome toxin-1 are significantly associated with nonmenstrual TSS. Lancet 1986; ii: 1149-1150.

4. Humphreys H, Keane CT, Hone R et al. Enterotoxin production by Staphylococcus aureus isolates from cases of septicaemia and from healthy carriers. J Med Microbiol $1989 ; 28$ : $163-172$. who survived. ${ }^{11}$ Surprisingly, the isolates from the patients with haematogenous osteomyelitis or arthritis produced enterotoxins less frequently than those from the other patients. However, this difference is probably coincidental rather than real, and no attempt was made to verify this observation by investigating a larger number of strains. Almost exactly the same incidence and pattern of enterotoxin production was observed among the strains causing communityacquired infections as compared with the strains causing nosocomial infection. This observation may merely reflect the fact that phage group patterns among nosocomial and community-acquired strains of $S$. aureus in Denmark are very similar, ${ }^{12}$ as enterotoxin production seems to be strongly correlated with particular phage groups. As reported by others, a high frequency of enterotoxin B production was found among strains of the phage complex 94/96 whereas a high frequency of enterotoxin $\mathrm{C}$ production was observed among strains of type 95 and the non-typable group. ${ }^{4,13,14}$ On the other hand, only three of 68 strains of phage group II produced enterotoxins., 14 However, it is of note that the nasal strains produced enterotoxins as frequently as the bacteraemia strains. The nasal strains belonging to the non-typable group produced enterotoxin $\mathrm{C}$ more frequently than the corresponding bacteraemia isolates, but apart from this difference, similar patterns of enterotoxin production were observed among the two groups. These results contradict those of Humphreys et al., who reported a significant difference between the incidence of enterotoxin production among isolates from patients with septicaemia compared with nasal strains (63\% versus $11 \%$, respectively). However, in this previous work relatively few isolates were investigated, i.e., 52 septicaemic and 27 nasal strains.

In conclusion, a similar incidence and pattern of enterotoxin production among strains of $S$. aureus was found, regardless of the presence or absence of endocarditis, source of acquisition, portal of entry and outcome of the infection, and even among strains isolated from the nares of healthy people. Thus, the concept that staphylococcal enterotoxins play an important role in staphylococcal diseases apart from food poisoning and TSS is not substantiated by the results of the present study.

5. Eriksen NHR, Espersen F, Rosdahl VT, Jensen K. Evaluation of methods for the detection of nasal carriage of Staphylococcus aureus. APMIS (in press).

6. Blair JE, Williams REO. Phage typing of staphylococci. Bull WHO 1961 ; 24 : 771-784.

7. Parker MT. The significance of phage-typing patterns in Staphylococcus aureus. In: Easmon CSF, Adlam C (eds) Staphylococci and staphylococcal infections, vol 1. Clinical and epidemiological aspects. London, Academic Press. 1983: 33-62.

8. Arvidson SO. Extracellular enzymes from Staphylococcus aureus. In: Easmon CSF, Adlam C (eds) Staphylococci and staphylococcal infections, vol 2. The organism in vivo and in vitro. London, Academic Press. 1983: 745-808.

9. Arbuthnott JP. Epidermolytic toxins. In: Easmon CSF, Adlam C (eds) Staphylococci and staphylococcal infections, vol 2. 
The organism in vivo and in vitro. London, Academic Press. 1983: 599-617.

10. Crass BA, Bergdoll MS. Toxin involvement in toxic shock syndrome. J Infect Dis 1986; 153: 918-926.

11. Ejlertson T, Jensen A, Lester A, Rosdahl VT. Epidemiology of toxic shock syndrome toxin-1 production in Staphylococcus aureus strains isolated from 1959 through 1990 in Denmark. Scand J Infect Dis (in press).

12. Rosdahl VT, Westh H, Jensen K. Antibiotic susceptibility and phage-type pattern of Staphylococcus aureus strains iso- lated from patients in general practice compared to strains from hospitalized patients. Scand J Infect Dis 1990; 22: 315-320.

13. Asheshov EH, Coe AW, Porthouse A. Properties of strains of Staphylococcus aureus in the 94, 96 complex. J Med Microbiol 1977; 10: 171-178.

14. Marples RR, Wieneke AA. Enterotoxins and toxic-shock syndrome toxin-1 in non-enteric staphylococcal disease. Epidemiol Infect 1993; 110: 477-488. 